\title{
TLR4 Asp299Gly and Thr399lle and TLR2 intron 2 microsatellite gene polymorphism in patients with acute biliary pancreatitis: Does it cause the disease?
}

\author{
Ender Anılır ${ }^{1}$, Filiz Özen², İbrahim Ali Özemir ${ }^{3}$, İbrahim Halil Yıldırım4, Çağrı Bilgiç̧, Orhan Alimoğlu
}

ABSTRACT

\begin{abstract}
Cite this paper as: Anılır E, Özen F, Özemir İA, Yıldııım IH, Bilgiç Ç, Alimoğlu 0. TLR4 Asp299Gly and Thr399lle and TLR2 intron 2 microsatellite gene polymorphism in patients with acute biliary pancreatitis: Does it cause the disease?. Turk J Surg 201834 (3): 191-197.
\end{abstract}

'Clinic of General Surgery, Amerikan Hospital, İstanbul, Turkey

${ }^{2}$ Department of Medical Genetics, İstanbul Medeniyet University School of Medicine, İstanbul, Turkey

${ }^{3}$ Department of General Surgery, İstanbul Medeniyet University School of Medicine, İstanbul, Turkey

${ }^{4}$ Department of Genetics, Dicle Üniversitesi School of Veterinary, Diyarbakır, Turkey

${ }^{5}$ Department of General Surgery, Koç University School of

Medicine, İstanbul, Turkey

This study was presented at the 20.National Surgery Congress, 13-17 April 2016, Antalya, Turkey.

Corresponding Author Ender Anilır

e-mail:drendersurgeon@gmail.com

Received: 20.02.2017

Accepted: 19.06.2017

Available Online Date: 28.08.2018

CCopyright 2018

by Turkish Surgical Association

Available online at

www.turkjsurg.com
Objectives: There has been coverage of Toll-like receptor 4 and Toll-like receptor 2 gene polymorphisms in inflam matory episodes in a number of studies. In view of the inflammatory nature of acute pancreatitis, we aimed to determine the predictive value of mutations in Asp299Gly and Thr399lle of the Toll-like receptor 4 gene, and the intron 2 microsatellite polymorphism of the Toll-like receptor 2 gene on the occurrence of acute biliary pancreatitis.

Material and Methods: The study included 86 patients for the Toll-like receptor 4 Thr399lle polymorphism, 100 patients for the Toll-like receptor 4 Asp299Gly polymorphism with acute biliary pancreatitis, and 101 healthy volunteers. At the same time, 93 patients and 92 healthy volunteers were included in the study to research the Toll-like receptor 2 intron 2 microsatellite polymorphism. Genotypes were determined using the restriction fragment length polymorphism analysis of PCR products and by an allele-specific PCR.

Results: The Toll-like receptor 4 Thr399lle homozygotes mutant variants $(p=0.005)$ and Toll-like receptor 2 MM genotype $(p<0.001)$ were detected with a significantly higher frequency in patients with acute biliary pancreatitis than in the healthy blood donors.

Conclusion: The Toll-like receptor 4 Asp299Gly and Thr399lle polymorphisms and the Toll-like receptor 2 intron 2 microsatellite polymorphism are statistically associated with ABP.

Keywords: Acute pancreatitis, biliary, gene polymorphism, Toll-like receptor 2, Toll-like receptor 4

\section{INTRODUCTION}

Acute pancreatitis (AP) is a disease common in the gastrointestinal system that induces acute abdominal pains and can lead to morbidity and sometimes mortality with an incidence rate of $13-45 / 100000$ (1). According to the Atlanta Classification, the severity of pancreatitis has been classified into three distinct categories of mild, moderate severe, and severe pancreatitis. Although mild and moderate severe pancreatitis is seen at the rate of $80 \%$, it recovers without any serious complications (2). Approximately $30 \%$ of the death cases have been reported to have arisen from acute pancreatitis (3). The causes of acute pancreatitis include iatrogenically toxic drugs following ERCP due to mechanical obstruction caused by gallstones, hypertriglyceridemia, alcohol, genetic predisposition, anatomical differences, primary inflammation (infectious, autoimmune), trauma, and idiopathic causes. In $60 \%-85 \%$ of patients, there is a history of gallstone or alcoholism (4-6). Of all these reasons, the most frequent etiological factor is the presence of gallstones (1). The most accepted theory in the pathophysiology of AP is the auto-digestion that occurs with trypsin activation in the pancreas parenchyma and the subsequent local and systemic inflammatory damage that develops $(2$, 4). Acute biliary pancreatitis (ABP) is the inflammation that develops as a result of auto-digestion and enzymatic parenchyma destruction with small gallstones, which as a gallstone complication, find a passageway to progress to the common bile duct and to be impacted to the ampulla of Vater $(7,8)$. In the pathogenesis of pancreatic inflammation, many immune factors and signaling pathways are involved in the innate immune system. The release of many proinflammatory factors plays a key role in the pathogenesis of AP (9). Toll-like receptors (TLR) with an important place in the pattern-recognition receptors (PRR) family have been researched in animal experiments and human-based clinical studies to investigate their role in the AP damage. Pathogen-associated molecular patterns (PAMPs), alarmins, and damage-associated molecular patterns (DAMPs) can serve as molecular signatures that can be recognized by the PRRs of innate immune system, starting an immunological response against the invasion, and if necessary, assisting in the activation of the adaptive immune system. Molecules found in microorganisms, but not in host cells are associated with PAMPs. Alarmins are endogenous molecules released into the extracellular compartment by activated or necrotic cells in response to stress or tissue damage. Even extracellular matrix molecules are alarmins when up-regulated upon injury or degraded following tissue damage. DAMPs constituted by alarmins and PAMPs, are the main targets of PRRs. PRRs are expressed on the cell surface or in intracellular compartments, but they can be secreted into the blood stream and tissue fluids as well (10).

TLR4 and TLR2 are members of the PRR family, which are frequently investigated as molecular mediators of the inflammation that constitutes AP (11). In different countries, genetic polymorphism has been in- 
vestigated using TLR4 Asp299Gly and Thr399lle with DNA isolation and guanine-thymine (GT) iterations in the TLR2 intron 2 region. The TLR4 Thr399lle polymorphism and the TLR2 intron 2 microsatellite polymorphism have been found to be significant in patients who died due to AP compared to CG in patients with severe AP (SAP) and AP. In another study, no significant difference was found in terms of the TLR4 Asp299Gly and Thr399lle polymorphism compared to CG in patients with AP (12-14).

In this study, it was analyzed whether the TLR4 Asp299Gly and Thr399lle and TLR2 intron 2 gene polymorphisms caused a tendency for the development of acute biliary pancreatitis and whether there was a difference between patients in terms of these gene polymorphisms according to the imaging findings and recurrent disease.

\section{MATERIAL AND METHODS}

This study included 105 patients who were hospitalized with a diagnosis of ABP and treated in the General Surgery Clinic between January 2010 and September 2014. The ABP patients were determined according to a sudden onset of upper abdominal quadrant pain in the back, amylase and lipase values at three times more than the normal values, and the presence of gallstone in the ultrasonographic imaging (USI) (15). The control group (CG) comprised 101 individuals with no pancreatitis or gallstone history and no other etiological factor or gallstones on abdominal USI. Informed consent for the genetic study participation was obtained from all the participants in the study and control groups. Analysis was made of whether there was a statistically significant difference between the ABP patients and the healthy population in terms of the TLR4 and TLR2 genetic polymorphism. The pancreatitis findings of the patients were also evaluated through computerized tomography $(C T)$. After the diagnosis of $A B P$, patients involved in the study were classified into categories according to the Revised Atlanta Classification of mild, moderate severe, and severe to evaluate the difference in genetic polymorphisms (16). In addition, the patients were compared in terms of the presence of polymorphism according to the factors considered important for the severity of inflammation, which were $>1$ attack, presence of pseudocyst, increasing prerenal fascia thickness on $\mathrm{CT}$, and fluid collection in two or more areas. These factors were analyzed to determine any differences. This study was approved by the Ethics Committee of İstanbul Medeniyet University (No. 2014-0064).

\section{DNA isolation and genetic polymorphism}

Peripheral blood samples taken from the patient and control groups were withdrawn into EDTA tubes and stored at $-20^{\circ} \mathrm{C}$. Then, the DNA isolations were obtained from these samples according to the manufacturer's protocol through a commercial kit (coded Bio Basic BS684-250 Ontario Canada). The PCR was performed with F: 5 '- ATT AGC ATA CTT AGA CTA CTA CCT CCA TG R: 5'-GAT CAA CTT CTG AAA AAG CAT TCC CAC-3' primers for the rs4986790 (Asp299Gly) polymorphism, and the obtained 249 bp amplicon was cut with Nco1 restriction enzyme and conducted in $3 \%$ agarose gel. Heterozygote gave AG allele $249+223+26$ bp bands, while homozygote was expected to give GG allele $223+26$ bp bands. For the rs4986791 (Thr399lle) polymorphism, the PCR was performed with F: $5^{\prime}$-GGT TGC TGT TCT CAA AGT GAT TTT GGG AGA A-3' and R: 5'- ACC TGA AGA
PCR products were cut through the (407 bp) Hinf I (Thermo Scientific) restriction enzyme and conducted in 3\% agarose gel. Expected band profiles were $407+378+29$ bp for heterozygous CT allele, and $378+29$ bp for the homozygous TT allele. The resulting band compositions were photographed, and analyses were carried out. To reveal the GT iterations in the intronic region of the TLR2 gene, the PCR was performed through the primers that enclose this region which are F: 5'-GCA TTG CTG AAT GTA TCA GGG A ve R: 5'-CTT GAG AAA TGT TTT CTA GGC. The PCR products were conducted in the $10 \%$ polyacrylamide gel electrophoresis; the results obtained were monitored, and the analyses were performed. A number of 16 or fewer of these iterations were evaluated as the $\mathrm{S}$ allele, those between 17 and 22 were evaluated as the $M$ allele, and those more than 22 were evaluated as the $L$ allele.

\section{Statistical Analysis}

Statistical Package for the Social Sciences (SPSS) version 22.0 (IBM Corp., Armonk, NY, USA) program was used in the data analysis. Conformity of the data to normal distribution and variance homogeneity were evaluated respectively through the Shapiro-Wilk and Levene tests. In comparing two independent groups, the Independent-Samples T-test was used together with Bootstrap results, while the Mann-Whitney $U$ test was used with the Monte Carlo simulation method. The one-way analysis of variance (Robust Test: Brown-Forsythe) was used together with the Bootstrap results, and Kruskal-Wallis $\mathrm{H}$ test was used with the Monte Carlo simulation method when comparing multiple groups with each other. In the comparison of categorical data, Pearson chi-squared and Fisher exact tests were used with the Monte Carlo simulation method. The quantitative data were expressed in the tables as mean \pm std. (standard deviation) and median range (Maximum-Minimum) values. The categorical data were stated as number ( $\mathrm{n}$ ) and percentage (\%). The data were analyzed at the $95 \%$ confidence interval, and a value of $\mathrm{p}<0.05$ was accepted as statistically significant.

\section{RESULTS}

Due to the development of hemolysis in the peripheral blood samples from patients, 100 patients were evaluated in the TLR4 Rs 4986790 polymorphism group, and 86 patients were evaluated in the Rs 4986791 polymorphism group. A total of 101 healthy individuals were included in TLR4-CG. The study was conducted with 93 patients in the TLR2 polymorphism group, and 92 healthy subjects for whom the genotypes belonging to TLR2 could work, to TLR2-CG. The mean age and sex ratios of all the patients were evaluated (Table 1). The TLR4 Rs 4986791 (Thr399lle) polymorphism was found to be statistically significant in terms of pancreatitis disease for acute biliary pancreatitis patients compared to the control group

Table 1. Distribution of the gender and age median values in the ABPG genetic polymorphism comparison

\begin{tabular}{|llc|}
\hline ABPG $n(\%)$ & & \\
Gender & Female & $69(65.7)$ \\
& Male & $36(34.3)$ \\
\hline \multirow{2}{*}{ Age } & Mean & $60.3+15.58$ \\
& Median & $61(92-22)$ \\
\hline
\end{tabular}

ABPG: acute biliary pancreatitis group 
Table 2. ABPG and CG TLR-4 Rs 4986791 genetic polymorphism comparison

\begin{tabular}{|c|c|c|c|c|c|}
\hline & & $\begin{array}{l}\text { ABPG } \\
\text { n (\%) }\end{array}$ & $\begin{array}{c}\text { CG } \\
\text { n (\%) }\end{array}$ & $\begin{array}{l}\text { Total } \\
\text { n (\%) }\end{array}$ & p \\
\hline \multirow[t]{2}{*}{ TLR-4 rs4986791 (Thr399lle) } & CC & $81(94.2)$ & $80(79.2)$ & $161(86.1)$ & $0.005^{a}$ \\
\hline & $\mathrm{CT}$ & $5(5.8)$ & $21(20.8)$ & $26(13.9)$ & $4.3(1.5-11.8)^{*}$ \\
\hline Total & & $86(100)$ & $101(100)$ & $187(100)$ & \\
\hline C allele & & $167(97)$ & $181(90)$ & $348(93)$ & 0.001 \\
\hline T allele & & $5(3)$ & $21(10)$ & $26(7)$ & $1.9(1.76-2.15)^{a-x}$ \\
\hline
\end{tabular}

Pearson Chi-Squared Test (Monte Carlo); aFisher Exact Test (exact); *Odds Ratio (95\% Confidence Interval)

ABPG: acute biliary pancreatitis group; CG: control group; TLR-4: toll like receptor-4

Table 3. ABPG and CG TLR-4 Rs 4986790 genetic polymorphism comparison

\begin{tabular}{|c|c|c|c|c|c|}
\hline & & $\begin{array}{l}\text { ABPG } \\
\text { n (\%) }\end{array}$ & $\begin{array}{c}\text { CG } \\
\text { n (\%) }\end{array}$ & $\begin{array}{l}\text { Total } \\
\text { n (\%) }\end{array}$ & p \\
\hline \multirow[t]{2}{*}{ TLR-4 rs4986790 (Asp299Gly) } & AA & $92(92)$ & $80(79.2)$ & $172(85.6)$ & $0.015^{\mathrm{a}}$ \\
\hline & AG & $8(8)$ & $21(20.8)$ & $29(14.4)$ & $3.02(1.3-7.2)^{*}$ \\
\hline Total & & $100(100)$ & $101(100)$ & $187(100)$ & \\
\hline A allele & & $192(96)$ & $181(90)$ & $373(93)$ & $<0.001^{\mathrm{a}}$ \\
\hline G allele & & $8(4)$ & $21(10)$ & $29(7)$ & $2.11(1.89-2.34)^{*}$ \\
\hline
\end{tabular}

Pearson Chi-Squared Test (Monte Carlo); aFisher Exact Test (exact); *Odds Ratio (95\% Confidence Interval) ABPG: acute biliary pancreatitis group; CG: control group; TLR-4: toll like receptor-4

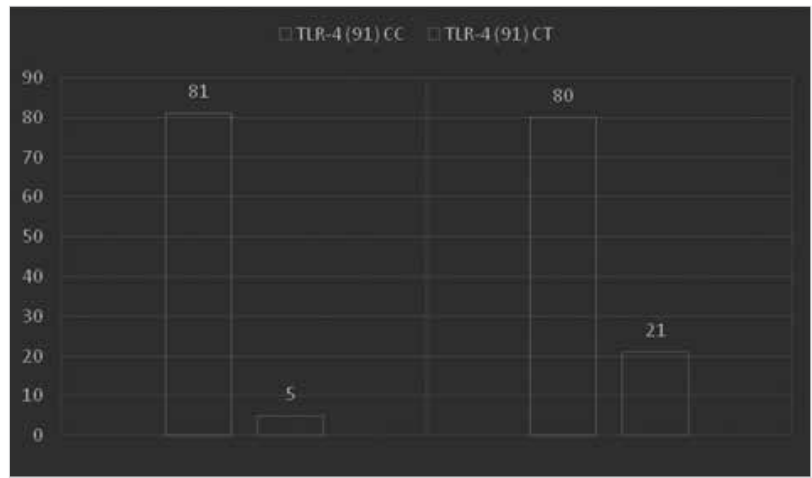

Figure 1. ABPG (n: 86, 94.2\%) and CG (n: 101, 79.2\%) Rs 4986791 genetic polymorphism comparison

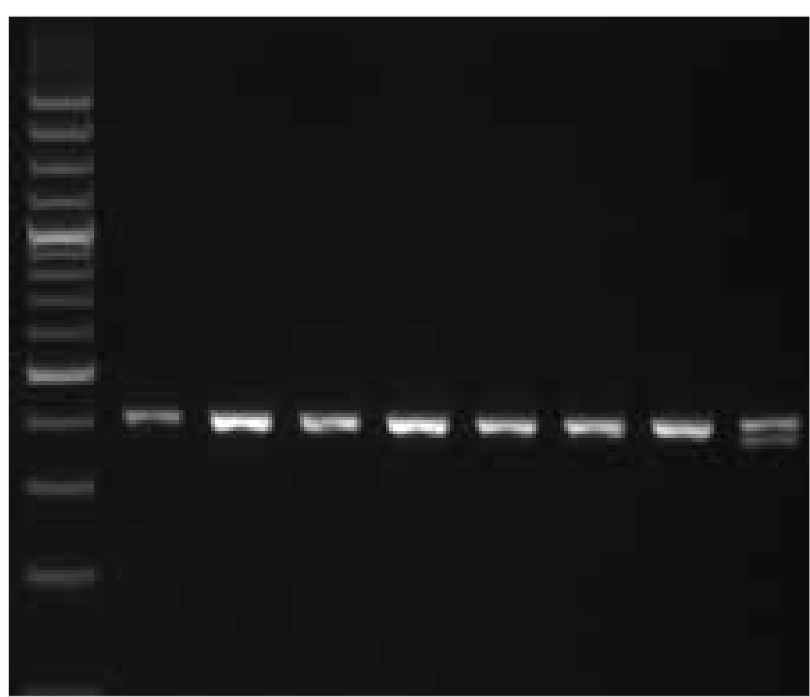

Figure 2. PRC appearance of the TLR4 Rs 4986791 (Thr399|le) genetic polymorphism homozygous alleles $(p=0.005)$. The rates of $C$ and $T$ alleles in the $C G$ and disease group were statistically significant $(p=0.001)$, and they were determined at 1.9 times more in the ABPG and CG respectively (Table 2, Figure 1, 2). No statistically significant difference was seen in the TLR4 Rs 4986790 polymorphism compared to the control group ( $p=0.015)$. However, it was seen that the rates of $A$ and $G$ alleles in the $C G$ and disease groups were statistically significant $(p=0.001)$, and they were 2.11 times more in the ABPG and CG respectively (Table 3 ). A statistically significant difference was not found between the female and male gender for patients with ABP in terms of the TLR4 Rs 4986790 and Rs 4986791 polymorphism ( $p=0.255 ; p=0.151$ ). No statistically significant difference was found between patients who had ABP for the first time and those who had experienced more than one attack in terms of TLR4 Rs 4986790 and Rs 4986791 polymorphism $(p=0.562, p=0.407)$. No significant difference was seen in patients with mild, moderate severe, and acute pancreatitis according to the Revised Atlanta Classification $(p=1, p=1)$. It was seen that the patients who had symptoms such as pseudocyst presence $(p=1, p=1)$, fluid collection two or more areas $(p=1, p=1)$ and increase in prerenal fascia thickness $(p=1, p=1)$ had no significant statistical value in terms of polymorphism compared to those without these symptoms (Table 4). It was seen that the polymorphism of the TLR2 intron 2 region was significantly higher in the $M M$ genotype $A B P G$ compared to CG. M alleles were found to be significantly higher in the patients $(p<0.001)$ (Table 5$)$. As only 1 patient had the SS and SL genotypes during the preparation of the TLR2 gene polymorphism statistical data, the statistics between the different genotypes of the severity and independent parameters belonging to the ABPG were left out of the analysis. No significant difference was observed between the female and male gender in patients with acute biliary pancreatitis in terms of the TLR2 polymorphism ( $p=0.533 ; p=0.630$ ). According to 
Table 4. TLR4 Rs 4986790 and Rs 4986791 genetic polymorphism according to gender, number of ABPG attacks, and Revised Atlanta Classification among the ABP patients and CT findings in ABPG

\begin{tabular}{|c|c|c|c|c|c|c|c|}
\hline & & \multicolumn{2}{|c|}{$\begin{array}{l}\text { TLR4 polymorphism } \\
\text { Rs } 4986790\end{array}$} & \multirow[b]{2}{*}{$p$} & \multicolumn{2}{|c|}{$\begin{array}{l}\text { TLR4 polymorphism } \\
\text { Rs } 4986791\end{array}$} & \multirow[b]{2}{*}{$p$} \\
\hline & & AG $(n: 8)$ & $A A(n: 92)$ & & $C T(n: 5)$ & CC (n:81) & \\
\hline \multirow[t]{2}{*}{ Gender* } & Female & $7(87.5)$ & $58(63)$ & 0.255 & $5(100)$ & $48(59.3)$ & 0.151 \\
\hline & Male & $1(12.5)$ & $34(37)$ & & $0(0)$ & $33(40.7)$ & \\
\hline \multicolumn{2}{|l|}{ Number of attacks $* *$} & $1(4-1)$ & $1(8-1)$ & 0.562 & $1(4-1)$ & $1(4-1)$ & 0.407 \\
\hline \multirow[t]{3}{*}{ Atlanta Criteria* } & Mild & $8(100)$ & $84(91.3)$ & 1 & $5(100)$ & 75 (92.6) & 1 \\
\hline & Moderate & $0(0)$ & $6(6.5)$ & & $0(0)$ & $5(6.2)$ & \\
\hline & Severe & $0(0)$ & $2(2.2)$ & & $0(0)$ & $1(1.2)$ & \\
\hline \multirow[t]{2}{*}{ Prerenal fascia thickness* } & Absent & $8(100)$ & $82(89.1)$ & 1 & $5(100)$ & $73(90.1)$ & 1 \\
\hline & Present & $0(0)$ & $10(10.9)$ & & $0(0)$ & $8(9.9)$ & \\
\hline \multirow[t]{2}{*}{ Pseudocyst* } & Absent & $8(100)$ & 87 (94.6) & 1 & $5(100)$ & $77(95.1)$ & 1 \\
\hline & Present & $0(0)$ & $5(5.4)$ & & $0(0)$ & $4(4.9)$ & \\
\hline \multirow{2}{*}{$\begin{array}{l}\text { Fluid collection in two } \\
\text { or more areas* }\end{array}$} & Absent & $8(100)$ & $82(89.1)$ & 1 & $5(100)$ & $73(90.1)$ & 1 \\
\hline & Present & $0(0)$ & $10(10.9)$ & & $0(0)$ & $8(9.9)$ & \\
\hline
\end{tabular}

Table 5. TLR2 intron 2 microsatellite polymorphism comparison between the ABPG and CG

\begin{tabular}{|c|c|c|c|c|c|c|c|}
\hline TLR-2 Genotypes & $\begin{array}{l}\text { ABPG } \\
n=93\end{array}$ & $\begin{array}{c}\text { Control } \\
n=92\end{array}$ & $p$ & TLR2 Allele & $\begin{array}{l}\text { ABPG } \\
n=93\end{array}$ & $\begin{array}{c}\text { Control } \\
n=92\end{array}$ & $\mathrm{p}$ \\
\hline SM & $16(17.2)$ & $25(27.2)$ & & $M$ & $126(68)$ & $92(50)$ & $<0.001$ \\
\hline SL & $1(1.1)$ & $9(9.8)$ & & $\mathrm{L}$ & $41(22)$ & $54(29)$ & \\
\hline MM & $50(53.8)$ & $20(21.7)$ & $<0.001$ & & & & \\
\hline ML & $10(10.8)$ & $27(29.3)$ & & & & & \\
\hline LL & $15(16.1)$ & $9(9.8)$ & & & & & \\
\hline
\end{tabular}

the Revised Atlanta Classification, no significant difference was found between patients who had mild, moderate severe, and acute pancreatitis $(p=0.727, p=0.764)$. There was no statistically significant difference between patients who had ABP for the first time and those who had more than one attack in terms of the TLR2 polymorphism ( $p=0.438, p=0.175)$. Patients with symptoms such as pseudocyst presence $(p=0.702, p=1)$, fluid collection in two or more areas $(p=0.211, p=0.430)$, and an increase in the prerenal fascia thickness $(p=0.211, p=0.430)$ had no significant statistical value in terms of polymorphism compared to those without these symptoms (Table 6).

\section{DISCUSSION}

Although it has been shown in many studies that an acute pancreatitis incidence is increasing, the mortality rate has been gradually reduced due to developments in diagnostic and therapeutic modalities (17). However, despite the advances in inspection modalities and research techniques, the $\mathrm{ABP}$ remains the most common cause of AP. With the presence of gallstones, it is known as a mechanical complication, but in general terms, the exact pathogenesis of APB has not yet been fully clarified $(2,18-20)$. Recently more and more solid evidence has demonstrated that the involvement of the immune system and, largely, release of multiple proinflammato- of AP. The early phase of severe AP progression is commonly accompanied by activation of monocytes, polymorphonuclear granulocytes, and macrophages, and the activated monocytes are the index of AP severity. Many factors and multiple pathways participated in the regulation of innate immune response of AP. TLRs can recognize pathogen-associated molecular patterns and protect bodies by initiating inflammatory reactions to destroy the invaders, thus playing pivotal roles in immune regulation. Studies on pathogenesis have shown that TLRs, which are members of the PRR family, are important components of the inflammation cascade, functioning as proinflammatory mediators affected by endogenous and exogenous sources in the TLR4 and TLR2 immune system $(9,10$, 21). To date, 29 single nucleotide polymorphisms of TLR4 have been detected, and the studies have been most frequently performed on Asp299Gly and Thr399lle (9). Studies of different ethnicities in different countries have tried to determine whether there is significant polymorphism susceptibility in AP patients compared to the healthy population, and whether the presence of polymorphism created a susceptibility to acute pancreatitis as defined in the Revised Atlanta Classification (9). In many studies performed on the Asp299Gly polymorphism, it has been shown that there was no genetic susceptibility due to the mutation of homozygous genotype in AP patients compared to CG (12-14, 22-24). Again, no significant result could 
Table 6. TLR2 intron 2 microsatellite polymorphism according to gender, Revised Atlanta Criteria, number of attacks among the ABP patients and CT findings in the ABP patient group

\begin{tabular}{|c|c|c|c|c|c|c|c|c|c|}
\hline & & \multicolumn{4}{|c|}{ TLR2 polymorphism } & \multicolumn{4}{|c|}{ TLR-2 polymorphism } \\
\hline & & ML n:10 & LL n:15 & MS n:16 & $M M n: 50$ & $\mathrm{p}$ & Insignificant n:27 & Significant n:66 & p \\
\hline \multirow[t]{2}{*}{ Gender* } & Female & $6(60)$ & $11(73.3)$ & $12(75)$ & $29(58)$ & 0.533 & $19(70.4)$ & $41(62.1)$ & 0.630 \\
\hline & Male & $4(40)$ & $4(26.7)$ & $4(25)$ & $21(42)$ & & $8(29.6)$ & $25(37.9)$ & \\
\hline \multirow[t]{3}{*}{ Atlanta Criteria* } & Severe & $10(100)$ & $15(100)$ & $15(93.8)$ & $44(88)$ & 0.727 & $26(96.3)$ & $60(90.9)$ & 0.764 \\
\hline & Mild & $0(0)$ & $0(0)$ & $1(6.3)$ & $5(10)$ & & $1(3.7)$ & $5(7.6)$ & \\
\hline & Moderate & $0(0)$ & $0(0)$ & $0(0)$ & $1(2)$ & & $0(0)$ & $1(1.5)$ & \\
\hline Number of attacks ** & & $1(4-1)$ & $1(4-1)$ & $1(2-1)$ & $1(8-1)$ & 0.438 & $1(4-1)$ & $1(8-1)$ & 0.175 \\
\hline \multirow[t]{2}{*}{ Prerenal fascia thickness* } & Absent & $10(100)$ & $15(100)$ & $15(93.8)$ & $43(86)$ & 0.211 & $26(96.3)$ & $59(89.4)$ & 0.430 \\
\hline & Present & $0(0)$ & $0(0)$ & $1(6.3)$ & $7(14)$ & & $1(3.7)$ & $7(10.6)$ & \\
\hline \multirow[t]{2}{*}{ Pseudocyst* } & Absent & $10(100)$ & $15(100)$ & 15 (93.8) & $46(92)$ & 0.702 & $26(96.3)$ & $62(93.9)$ & 1 \\
\hline & Present & $0(0)$ & $0(0)$ & $1(6.3)$ & $4(8)$ & & $1(3.7)$ & $4(6.1)$ & \\
\hline \multirow{2}{*}{$\begin{array}{l}\text { Fluid collection in two } \\
\text { or more areas* }\end{array}$} & Absent & $10(100)$ & $15(100)$ & 15 (93.8) & $43(86)$ & 0.211 & $26(96.3)$ & $59(89.4)$ & 0.430 \\
\hline & Present & $0(0)$ & $0(0)$ & $1(6.3)$ & $7(14)$ & & $1(3.7)$ & $7(10.6)$ & \\
\hline
\end{tabular}

One-Way Analysis of Variance (Brown-Forsythe) (Method: Bootsrap ); Kruskal-Wallis Post Hoc Test (Monte Carlo); Independent T-Test (Bootstrap); Mann-Whitney U Test (Monte Carlo); Pearson Chi-Squared Test (Monte Carlo); Fisher Exact Test (Monte Carlo); *: n (\%), **: median (range)

be obtained in studies on the other frequently investigated Thr399lle polymorphism (12-14). In many studies performed on the Asp299Gly and Thr399lle genetic mutations, it has been seen that the AP patient groups were heterogeneous etiologically. However, in the current study, genetic polymorphism was investigated in a more specific group by including the ABP patients.

According to the Revised Atlanta Classification, the severe form of AP, which is clinically divided as mild (MAP), moderate severe, and severe (SAP) and in which pancreatic necrosis may also be seen and there is high morbidity and mortality due to sepsis and SIRS, was investigated in terms of the TLR4 polymorphism disease, which is considered to possibly be the molecular reason for the increased inflammatory response and gram-negative bacteria infection effect. Studies where the Asp299Gly polymorphism has been analyzed in SAP patients compared to MAP, no significant result has been determined in respect of SAP $(9,12,14,23,24)$. In another extensive study, no significant result was determined in favor of the TLR4 Asp299Gly and Thr399lle polymorphism. In the same study, no significant difference was seen between the SAP and MAP patients in terms of genetic polymorphism (25). However, in a study that involved 310 AP patients, 115 patients were diagnosed with pancreatic necrosis and the Asp299Gly polymorphism was investigated, and it was seen that morbidity due to gram-infection and incidence of pancreatic necrosis had increased in patients with mutation compared to the healthy control group and patients without polymorphism (11).

In the clinical analysis of the current study, which was performed according to the Revised Atlanta Classification, it was observed that the TLR4 Asp299Gly and Thr399lle polymorphism and the TLR2 intron 2 microsatellite polymorphism did not create any significant differences in patients with different pancreatitis severities, and there was no connection between the genetic polymorphism and pancreatitis severity.
In several studies, it has also been attempted to evaluate the severity of illness with $\mathrm{CT}$ findings. The Balthazar classification, perirenal space findings, and fascia findings are important among these evaluations. Fluid accumulation in the peripancreatic area and an increase in the thickness of the perirenal fascia, which may be evaluated as the indicators of transition from mild to moderate severe illness, are remarkable imaging findings on CT (26-29). In addition, pancreatic pseudocyst, which rarely develops due to $\mathrm{AP}$, occurs with the localization of peripancreatic fluid 4 weeks after the acute attack. Parenchymal necrosis development in the distal pancreatic remnant created by the neck and body sections of the pancreas may also cause the formation of pseudocyst and necrosis, is known to be an important indicator of the severity of AP (16). Although the severity of biliary pancreatitis seems to be connected with the predisposition of the patient, animal experiments and clinical studies have shown that the severity of illness could be more closely related to the continuation of the common bile duct obstruction (3033). Gallstone disease represents the most common condition associated with acute recurrent pancreatitis (ARP) in Western countries. The most common causes of ARP are obstruction of the main pancreatic duct or pancreatico-biliary junction, genetic mutations, and alcohol consumption. If $A B P$ is in question in ARP, mechanical obstruction and genetic mutation must be a relevant reason of more than one attack (34).

In this study, no relationship was determined between the CT findings, patients having more than one attack, and the TLR4 and TLR2 genetic polymorphism, which may be the indicators of the severity of illness.

As a member of the PRR family and a pro-inflammatory molecule, the TLR2 polymorphism has been investigated for AP as it has for different diseases. TLR2 is expressed on the plasma membrane of a large diversity of cells, including monocytes and macrophages, dendritic cells, polymorphonuclear leukocytes, B cells, T cells, and microglia. This PRR recognizes a wide 
range of DAMPs. Usually associated with the innate immune response against Gram-positive bacteria. Besides its role in infectious diseases, TLR2 has also been reported to be involved in several non-infectious disorders including AP (11). In a study, the SS and SL genotypes were observed to be higher in AP patients, and S allele were observed to be higher in SAP patients compared to MAP and finally, it was attempted to reveal that the AP patients showed a higher rate of TLR2 intron 2 polymorphism compared to CG. However, as the study in question was limited to a certain population, more extensive studies are needed $(11,13)$. In another study where many TLR subgroups including TLR2 were analyzed, no significant finding could be determined in respect to AP and SAP in terms of the TLR2 genetic polymorphism (22).

In this study, the TLR2 intron 2 region microsatellite polymorphism was found to be significant in the MM genotype patients compared to CG $(p<0.001)$. The MM genotype was observed to be associated with ABP. This study may expose that, role of TLR2 and TLR4 in early inflammation cascade, may be the cause of $A B P$, although there isn't no relationship between polymorphism and severity parameters.

\section{CONCLUSION}

The results of this study showed that although the TLR4 Rs 4986791 (Thr399lle) polymorphism and the TLR2 intron 2 MM genotype polymorphism are not important for severe illness, they are significant in terms of creating susceptibility for the ABP disease compared to CG. More extensive genetic research should be conducted, to determine the possibility of eliminating the cause of disease with early cholecystectomy applied to patients with genetic polymorphism, before the development of pancreatitis.

Ethics Committee Approval: Ethics committee approval was received for this study from the Ethics Committee of of İstanbul Medeniyet University (No. 2014-0064).

Informed Consent: Verbal informed consent was obtained from patients who participated in this study.

Peer-review: Externally peer-reviewed.

Author Contributions: Concept - E.A.; Design - E.A., I.A.Ö.; Supervision - O.A.; Resource - E.A.; Materials - E.A., I.H.Y.; Data Collection and/ or Processing - E.A., C.B.; Analysis and/or Interpretation - F.Ö.; Literature Search - E.A.; Writing Manuscript -E.A.; Critical Reviews - I.H.Y., F.Ö., I.A.Ö.

Conflict of Interest: The authors have no conflicts of interest to declare.

Financial Disclosure: The authors declared that this study has received no financial support.

\section{REFERENCES}

1. Yadav $D$, Lowenfels AB. The epidemiology of pancreatitis and pancreatic cancer. Gastroenterology 2013; 144: 1252-1261. [CrossRef]

2. Meher S, Mishra TS, Sasmal PK, Rath S, Sharma R, Rout B, et al. Role of Biomarkers in Diagnosis and Prognostic Evaluation of Acute Pancreatitis. J Biomark 2015; 2015: 519-534. [CrossRef]

3. Loveday BP, Srinivasa S, Vather R, Mittal A, Petrov MS, Phillips AR et al. High quantity and variable quality of guidelines for acute pancreatitis: a systematic review. Am J Gastroenterol 2010; 105: 1466-1476. [CrossRef]

4. Weitz G, Woitalla J, Wellhöner P, Schmidt K, Büning J, Fellermann K. Does etiology of acute pancreatitis matter? A review of 391 consecutive episodes. JOP 2015; 16: 171-175.

5. Phillip V, Steiner JM, Algül H. Early phase of acute pancreatitis: Assessment and management. World J Gastrointest Pathophysiol 2014; 5: 158-168. [CrossRef]

6. Yadav $D$, Lowenfels $A B$. Trends in the epidemiology of the first attack of acute pancreatitis: a systematic review. Pancreas 2006; 33:323-330. [CrossRef]

7. Lindkvist B, Appelros S, Manjer J, Borgastrom A. Trends in incidence of acute pancreatitis in a Swedish population: is there really an increase? Clin Gasteroenterol Hepatol 2004; 2: 831-837. [CrossRef]

8. Frey $\mathrm{CF}$, Zhou H, Harvey DJ, White RH. The incidence and case fatality rates of acute biliary, alcoholic, and idiopathic pancreatitis in California, 1994-2001. Pancreas 2006; 33: 336-44. [CrossRef]

9. Zhou XJ, Cui Y, Cai LY, Xiang JY, Zhang Y. Toll-like receptor 4 polymorphisms to determine acute pancreatitis susceptibility and severity: a meta-analysis. World J Gastroenterol 2014; 20: 66666670. [CrossRef]

10. Johnson GB, Brunn GJ, Platt JL. Cutting edge: an endogenous pathway to systemic inflammatory response syndrome (SIRS)-like reactions through Toll-like receptor 4. J Immunol 2004; 172: 20-24. [CrossRef]

11. Vaz J, Akbarshahi H, Andersson R. Controversial role of toll-like receptors in acute pancreatitis. World J Gastroenterol 2013; 19: 616-630. [CrossRef]

12. Guenther A, Aghdassi A, Muddana V, Rau B, Schulz HU, Mayerle $J$, et al. Toll-like receptor 4 polymorphisms in German and US patients are not associated with occurrence or severity of acute pancreatitis. Gut 2010; 59: 1154-1155. [CrossRef]

13. Takagi $Y$, Masamune A, Kume K, Satoh A, Kikuta K, Watanabe T, et al. Microsatellite polymorphism in intron 2 of human Toll-like receptor 2 gene is associated with susceptibility to acute pancreatitis in Japan. Hum Immunol 2009; 70: 200-204. [CrossRef]

14. Hofner P1, Balog A, Gyulai Z, Farkas G, Rakonczay Z, Takács T. et al. Polymorphism in the IL-8 gene, but not in the TLR4 gene, increases the severity of acute pancreatitis. Pancreatology 2006; 6: 542-548. [CrossRef]

15. Kimura $Y$, Takada T, Kawarada $Y$, Hirata K, Mayumi T, Yoshida M, et al. JPN Guidelines for the management of acute pancreatitis: treatment of gallstone-induced acute pancreatitis. J Hepatobiliary Pancreat Surg 2006; 13: 56-60. [CrossRef]

16. Banks PA, Bollen TL, Dervenis C, Gooszen HG, Johnson CD, Sarr $M G$, et al. Acute Pancreatitis Classification Working Group Classification of acute pancreatitis--2012: revision of the Atlanta classification and definitions by international consensus. Gut 2013; 62: 102-111. [CrossRef]

17. Lowenfels $A B$, Maisonneuve $P$, Sullivan $T$. The changing character of acute pancreatitis: epidemiology, etiology, andprognosis. Curr Gastroenterol Rep 2009; 11: 97-103. [CrossRef]

18. Bhatia M, Wong FL, Cao Y, Lau HY, Huang J, Puneet Pet, al. Pathophysiology of acute pancreatitis. Pancreatology 2005; 5: 132-144. [CrossRef]

19. Gabbrielli A, Pezzilli R, Uomo G, Zerbi A, Frulloni L, Rai PD, et al. ERCP in acute pancreatitis: What takes place in routine clinical practice? World J Gastrointest Endosc 2010; 2: 308-313. [CrossRef]

20. Afghani E, Pandol SJ, Shimosegawa T, Sutton R, Wu BU, Vege SS, et al. Acute Pancreatitis-Progress and Challenges: A Report on an International Symposium. Pancreas 2015; 44: 1195-1210. [CrossRef]

21. Matsumura N1, Takeyama Y, Ueda T, Yasuda T, Shinzeki M, Sawa H, et al. Decreased expression of Toll like receptor 2 and 4 on macrophages in experimental severe acute pancreatitis. Kobe J Med Sci 2007; 53: 219-227. 
22. Gao HK, Zhou ZG, Li Y, Chen YQ. Toll-like receptor 4 Asp- 299Gly polymorphism is associated with an increased risk of pancreatic necrotic infection in acute pancreatitis: a study in the Chinese population. Pancreas 2007; 34: 295-298. [CrossRef]

23. Zhang $D$, Zheng $H$, Zhou Y, Yu B, Li J. TLR and MBL gene polymorphisms in severe acute pancreatitis. Mol Diagn Ther 2008; 12 : 45-50. [CrossRef]

24. Chen WL, Li WL, Su JR, Han SG, Yi XY. Analysis of Toll-like receptor 4 polymorphisms in patients with acute pancreatitis. Chin Remed Clinic 2009; 9: 685-688.

25. Matas-Cobos AM, Redondo-Cerezo E, Alegría-Motte C, MartínezChamorro A, Saenz-López $P$, Jiménez $P$, et al. The role of Toll-like receptor polymorphisms in acute pancreatitis occurrence and severity. Pancreas 2015; 44: 429-433.

26. Banday IA, Gattoo I, Khan AM, Javeed J, Gupta G, Latief M. Modified Computed Tomography Severity Index for Evaluation of Acute Pancreatitis and its Correlation with Clinical Outcome: A Tertiary Care Hospital Based Observational Study. J Clin Diagn Res 2015; 9: TC01-TC05. [CrossRef]

27. Ishikawa K, Idoguchi K, Tanaka H, Tohma Y, Ukai I, Watanabe H, et al. Classification of acute pancreatitis based on retroperitoneal extension: application of the concept of interfascial planes. Eur J Radio 2006; 60: 445-452. [CrossRef]
28. Li XH, Zhang XM, Ji YF, Jing ZL, Huang XH, Yang L, et al. Renal and perirenal space involvement in acute pancreatitis: An MRI study. Eur J Radiol 2012; 81: e880-e887. [CrossRef]

29. Qi R, Zhou X, Yu J, Li Z. In vivo anatomical study of inferior attachment of renal fascia in adult with acute pancreatitis as shown on multidetector computed tomography. Sheng Wu Yi Xue Gong Cheng Xue Za Zhi 2014; 31: 332-335, 346.

30. Hirano T, Manabe T. A possible mechanism for gallstone pancreatitis: repeated short-term pancreaticobiliary duct obstruction with exocrine stimulation in rats. Proc Soc Exp Biol Med 1993; 202: 246-252. [CrossRef]

31. Rünzi M, Saluja A, Lerch MM, Dawra R, Nishino H, Steer ML. Early ductal decompression prevents the progression of biliary pancreatitis: an experimental study in the opossum. Gastroenterology 1993; 105: 157-164. [CrossRef]

32. Senninger N, Moody FG, Coelho JC, Van Buren DH. The role of biliary obstruction in the pathogenesis of acute pancreatitis in the opossum. Surgery 1986; 99: 688-693.

33. Pezzilli R, Billi P, Barakat B, Baroncini D, D'Imperio N, Miglio F. Effects of early ductal decompression in human biliary acute pancreatitis. Pancreas 1998; 16: 165-168. [CrossRef]

34. Testoni PA. Acute recurrent pancreatitis: Etiopathogenesis, diagnosis and treatment. World J Gastroenterol 2014; 20: 16891-16901. [CrossRef] 